\title{
Some aspects of metal ion transport and in silico gene expression analysis of potassium/sodium ion transporters, channels and exchangers in root nodules
}

\author{
Natalia Trifonova, Maria Koroleva, and Elena Fedorova \\ K. A. Timiryazev Institute of Plant Physiology, Russian Academy of Sciences, \\ ul. Botanicheskaya, 35, Moscow, 127276, Russian Federation \\ Address correspondence and requests for materials to Elena Fedorova, \\ elenafedorova06@mail.ru
}

\begin{abstract}
Rhizobia establish a symbiotic relationship with legumes, which results in the formation of root nodules, the ecological niche for intracellular rhizobia. The infected cell of a root nodule is a special integral unit of plant and nitrogen fixing rhizobia. Nodules tend to be very sensitive to ionic stresses, such as salt stress. High vulnerability toward ionic stresses might be due to defects in ion balance and transport in the infected tissue. The purpose of this minireview is to summarize the current data regarding metal ion transport in the root nodule, with particular emphasis on potassium/sodium ion transport. A bioinformatic approach and in silico gene expression analysis have been used to obtain some insight for $\mathrm{K}^{+} / \mathrm{Na}^{+}$transporter channels and exchangers in root nodule developmental zones.
\end{abstract}

Keywords: symbiosis, root nodule, infected cell, symbiosome, ion transporters

\section{Introduction}

Citation: Trifonova, $\mathrm{N}$, Koroleva, $\mathrm{M}$ and Fedorova, E. 2021. Some aspects of metal ion transport and in silico gene expression analysis of potassium/sodium ion transporters, channels and exchangers in root nodules. Bio. Comm. 66(1): 55-65. https://doi.org/10.21638/spbu03.2021.107

Authors' information: Natalia Trifonova, PhD Student, Engineer, orcid.org/0000-0002 3493-9994; Maria Koroleva, Master Student, Engineer, orcid.org/0000-0001-9920-7383; Elena Fedorova, PhD, Leading Researcher, orcid.org/0000-0003-3953-1282

Manuscript Editor: Nikolay Provorov, All-Russia Research Institute for Agricultural Microbiology, Saint Petersburg, Russia

Received: September 8, 2020;

Revised: November 30, 2020;

Accepted: December 21, 2020.

Copyright: @ 2021 Trifonova et al. This is an open-access article distributed under the terms of the License Agreement with Saint Petersburg State University, which permits to the authors unrestricted distribution, and self-archiving free of charge.

Funding: The work was supported by RFBR (Russian Foundation for Basic Research, grant 19-04-00570 to E.E.F.). The authors would like to thank the Ministry of Science and Higher Education of the Russian Federation for covering the basic supplies for the research (0087-2019-0013).

Soil bacteria from the family Rhizobiaceae are able to form a symbiotic relationship with leguminous plants. Symbiosis gives plants access to ammonia converted from the nitrogen gas by bacterial enzyme nitrogenase. The initial steps of symbiosis consist of signal exchange between two potential partners. Rhizobia recognize the flavonoids, secreted by legumes, and the Nod factors produced by the bacteria trigger a signal transduction pathway in the root cells that activates root nodule organogenesis (Oldroyd, 2013; Geurts et al., 2016; Roy et al., 2020).

Completely new organs, the root nodules, are formed by a new meristem, which is initiated by the dedifferentiation of root cortical cells. The spatial pattern of meristem initiation and persistence determines the main differences between nodule types. Nodules of so-called indeterminate type of growth (Medicago truncatula, Pisum sativum) develop as elongated cylindrical structures due to the meristem situated on the nodule apex, and the nodules with determinate type of growth (Lotus japonicus, Glycine max) develop in spherical form due to the short living meristem situated in the centre of the primordia (Vasse et al., 1989; Kondorosiet et al., 2013; Mergaert et al.,2020).

Rhizobia start to populate the host cells' apoplast, forming small local colonies, and in the next stage of infection they invade the symplastic space of the host cells via infection threads in the so-called zone of infection (Vasse et al., 1990). Infected cells undergo polyploidization, enlarge, and differentiate into fully matured symbiotic cells that contain nitrogen-fixing bacteroids (Kondorosiet al., 2013; Mergaert et al., 2020). The zone of the nodule, composed of mature infected cells, is defined as the zone of nitrogen fixation. The lifespan of an infected cell is around 16-20 days before the symbiotic relations are terminated, nitrogen fix- 
ation ceases, and the cell undergoes lysis. For information concerning the morphology and organogenesis of root nodules we would like to refer to excellent reviews published recently (Oldroid et al., 2013; Kondorosiet al., 2013; Mergaert et al., 2020).

About half of the cells of the nodule inner cortex contain rhizobia, hence are infected. The intracellular form of bacteria, the symbiosome - or nitrogen-fixing "organelle" - is a host plant-derived membrane vesicle housing single or several bacteria (Parniske, 2018; Coba et al., 2019; Roy et al., 2020). Thousands of symbiosomes are kept within the infected cell's symplast, separated from the host cytoplasm by a host cell-derived membrane. This interface, the symbiosome membrane, is the key element of the symbiotic relationship. The transport of molecules and ions necessary for bacteria metabolism through the symbiosome membrane ensures the intracellular lifestyle of rhizobia and the functional activity of root nodules. Mature symbiosomes appear to have a unique mosaic identity, combining plasma membrane and late endosomal markers due to the retargeting of some host cell proteins toward the symbiosome membrane (Limpens et al., 2009; Ivanov et al., 2012; Gavrin et al., 2016, 2017). The infected cell is key to the maintenance of symbiotic interactions; the unique biology of this special integral unit of plant and bacteria justifies the study of the infected cell's development and special features.

One of the important factors in the development of an infected cell is ion homeostasis. The data obtained in recent years in this area have opened an unexplored field of research. However, it turns out that integral analysis of data obtained by different methods like genomics, cell biology and plant physiology is needed. The purpose of this minireview is to summarize the current data regarding metal ion transport in the root nodule with an emphasis on potassium/sodium ion transport, and to outline putative future research in this area. In the first part of this minireview we will briefly summarize the recent data concerning the host plant transporters of metal ions required for metalloenzymes, cofactors of key proteins involved in the process of nitrogen fixation, oxygen balance in the nodule and other functions. In the second part of the minireview we will focus on the putative channels and transporters of potassium and sodium in nodule developmental zones.

\section{Ions required for the functional activity of infected cells in the root nodule}

Infected cells of the root nodule have a distinct requirement for a number of ions. The process of nitrogen fixation is based on assembly and functionality of several metalloproteins. Specialized metalloenzymes and proteins are involved in the enzymatic reaction of nitrogen fixation and the maintenance of oxygen level in infected cells. These genes and metalloproteins have been intensively studied and reviewed in recent years (Rubio and Ludden, 2008; Brear et al., 2013; Mendoza-Suárez et al., 2020; Roy et al., 2020). Several metal ions are cofactors of metalloenzymes such as (Fe)-hemoglobins, (Fe-Mo)nitrogenase, (Fe-S)-nitrogenase, $(\mathrm{Cu}-\mathrm{Fe})$-cytochromes, and transcription factors including zinc finger (Roy et al., 2020). The search for the specific transporters by methods of forward and reverse genomics have been performed with the aim of understanding how these ions are transported to the nodule (Brear et al., 2013, 2020; Roy et al., 2020). Below we briefly describe the recent publication regarding ion transporters in the root nodule and infected cell. A schematic diagram of localization of transporters is given in Figure 1.

Molybdenum is the ion crucial for nitrogenase, a two-component metalloenzyme, that has molybdenum in the iron-molybdenum cofactor, the active center of the enzyme. Members of the molybdate transporter family Molybdate Transporter type 1 (MOT1) were identified in M.truncatula (Tejada-Jimenez et al., 2017). Expression analysis, yeast toxicity assays, confocal microscopy, and phenotypical characterization of Transposable Element from Nicotiana tabacum (Tnt1) insertional mutant line have been carried out in MtMOT1.3. Among the five MOT1 members present in the M.truncatula genome, MtMOT1.3 is the only one uniquely expressed in nodules. MtMOT1.3 shows molybdate transport capabilities when expressed in yeast. Immunolocalization studies revealed that MtMOT1.3 is located in the plasma membrane of nodule cells. A mot1.3-1 knockout mutant showed impaired growth concomitant with a reduction of nitrogenase activity. This phenotype was rescued by increasing molybdate concentrations in the nutritive solution, or upon addition of an assimilable nitrogen source. Furthermore, mot1.3-1 mutant plants transformed with a functional copy of MtMOT1.3 have shown a wild-typelike phenotype. These data are consistent with a model in which MtMOT1.3 is responsible for introducing molybdate into nodule cells, which is later used to synthesize functional nitrogenase (Tejada-Jimenez, 2017). In a recent study Gil-Díezetal et al. (2019) performed research on MtMOT1.2, another molybdenum transporter of this family. They characterized the function of MtMOT1.2 as a likely candidate for molybdate uptake from the vasculature by endodermal cells (Gil-Díezetal et al., 2019). MtMOT1.2 is located in the endodermis of the nodule and root vascular cylinders, in the plasma membrane and in an endomembrane compartment. It has shown molybdate uptake capabilities in yeast, and its mutation in M. truncatula leads to a reduction in the nitrogenase activity of nodules; likely it is the result of the reduction in molybdate delivery to the infected cells. The function of MtMOT1.2 seems to be relevant for symbiotic nitrogen 


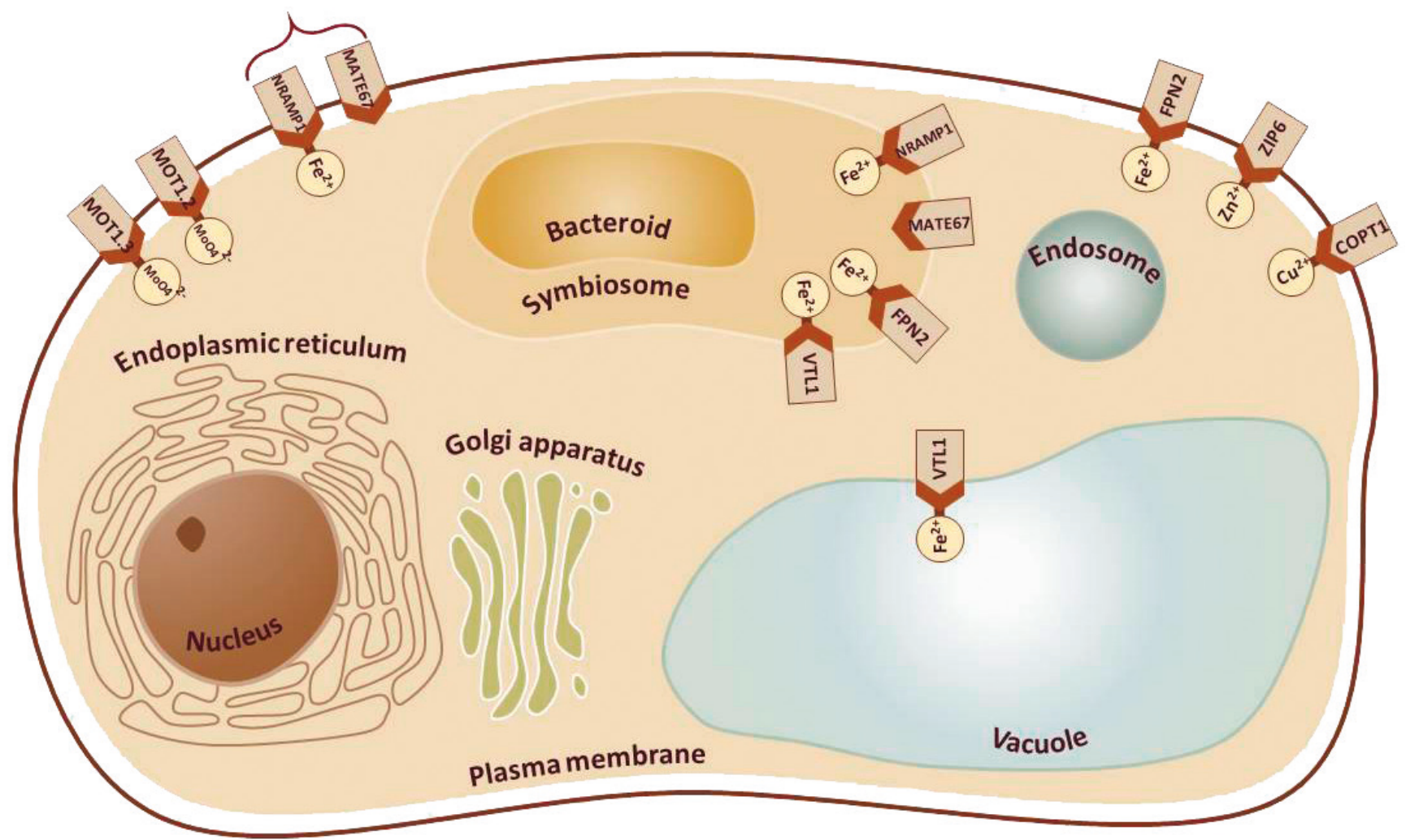

Fig. 1. The location of metal ion transporters involved in the enzymatic reaction of nitrogen fixation and the maintenance of oxygen level in infected cells.

COP1, Copper membrane transporter; FPN2, Ferroportin2, Fe2 ${ }^{+}$translocator; MATE67, organic chelator, citrate efflux transporter; MOT1-2, Molybdate Transporter type 1; MOT1-3, Molybdate Transporter type 1; NRAMP1, Resistance-Associated Macrophage Protein1, Fe2 ${ }^{+}$translocator; ZIP6, zinc transporterMtZIP6 (Zinc-IronPermease6); VTL1,Vacuolar Iron Transporter1.

fixation, given the fact that its mutation has no effect on plants grown on nitrate.

It can be assumed that molybdenum transporters MtMOT1.2 and MtMOT1.3 are essential for symbiotic nitrogen fixation (Fig. 1). However, the localization of these transporters in the symbiosome membrane has not yet been proven.

Copper membrane transporters of the COPT family have been identified by Senovilla et al. (2018) in M. truncatula. MtCOPT1 has been found to be the only nodule-specific COPT gene from the group of eight COPT transporters. Senovilla et al. (2018) performed phenotypical characterization of COPT1 Tnt 1 insertional mutant, yeast complementation assays, expression analysis and confocal microscopy. MtCOPT1 has been located in the plasma membrane in young root nodule cells up to the early fixation zone. Mutation of MtCOPT1 results in diminished nitrogenase activity in nodules. Senovilla et al. (2018) have pointed out that such consequences can be a secondary effect due to the loss of a $\mathrm{Cu}$-dependent function of cytochrome oxidase activity in bacteroids. Such effects result in the reduction of biomass production when the plant obtains its nitrogen exclusively from symbiotic nitrogen fixation, which proves the specific requirement of this ion for the symbiosomes (Fig. 1).
Iron. Iron deficiency is a nutritional problem in plants which reduces productivity and growth. Deficiency in iron can affect initiation and development of the nodule (Brear et al., 2013, 2020; Krivoruchko et al., 2018; Roy et al., 2020). Iron is required for iron- and molybdenum-iron proteins of nitrogenase, leggemoglobin, respiratory oxidases, and is essential for some enzymes of the bacterial respiratory chain. According to the data of Rodríguez-Haas et al. (2013), obtained by the methods of metal visualization and synchrotron-based $\mathrm{x}$-ray fluorescence studies, most of the iron is delivered via vascular bundles to the apoplast of the zone of infection. In the zone of active nitrogen fixation, iron is mostly localized in symbiosomes (Rodríguez-Haas et al., 2013). In their interesting work, Escudero et al. (2020) have shown that Ferroportin2 (MtFPN2) is able to mediate iron import into symbiosomes in M. truncatula nodules. MtFPN2 is located in intracellular membranes in the nodule vasculature and in inner nodule tissues, as well as in the symbiosome membranes in the interzone and early-fixation zone of the nodules. Loss of function of MtFPN2 alters iron distribution in nodules, reducing nitrogenase activity and biomass production. Using promoters with different tissue activity to drive MtFPN2 expression in MtFPN2 mutants, Escudero et al. (2020) de- 
termined that expression in the inner nodule tissues is sufficient to restore the phenotype, while confining that MtFPN2 expression to the vasculature did not improve the mutant phenotype.

The other plasma membrane iron transporter that transports iron from the apoplast into infected nodule cells is Resistance-Associated Macrophage Protein 1 (MtNRAMP1) (Tejada-Jiménez et al., 2015). Immunolocalization studies indicate that MtNramp1 is mainly targeted to the plasma membrane. A loss-of-function nramp1 mutant exhibited reduced growth compared with the wild type under symbiotic conditions, but not when fertilized with mineral nitrogen. The mutant nodules have low nitrogenase activity. Exogenous iron and expression of wild-type MtNramp1 in mutant nodules have increased nitrogen fixation to normal levels. These data are consistent with a model in which MtNramp1 is the main transporter responsible for apoplastic iron uptake by rhizobia-infected cells in zone II of the root nodule. Among the seven identified members of the M. truncatula Nramp family, MtNramp1 has shown the highest expression level in nodules. Yeast complementation assays indicated that MtNramp 1 can transport iron and manganese into cells, which is consistent with a putative role in iron uptake by nodule cells infected with rhizobia. However, for this to be the case in M.truncatula, it is puzzling that MtNramp1 is not found in the plasma membrane of the cells from zone II (Fig. 1).

The plant vacuole is the organelle involved in the maintenance of iron homeostasis in the cell. The homologs of tonoplast-localized Vacuolar Iron Transporter1 of Lotus yaponicum (SEN1) and Glycine max (GmVTL1a and GmVTL1b) are essential for nitrogen fixation (Hakoyama et al., 2012; Brear et al., 2020). Expression of SEN1 gene was detected exclusively in nodule-infected cells and increased during nodule development. The expression analysis has revealed a low expression of Nif gene in the nodules of sen 1 mutant nodules compared with wild type nodules, which means the mutation affects nitrogen fixation activity. The differentiation of symbiosomes was impaired at a very early stage of nodule development (Hakoyama et al., 2012). The soybean has two homologs of this gene, GmVTL1a and GmVTL1b (Brear et al., 2020). The methods of yeast complementation, real-time PCR and proteomics were used by Brear et al. (2020) to prove that these genes are the putative soybean iron transporters. Brear et al. (2020) have characterized GmVTL1a functionality using complementation in plant mutants, hairy root transformation and microscopy. The expression analysis of GmVTL1a in nodules using a promoter-GUS fusion has shown that the expression has been detected in large infected cells of the inner cortex and in cells surrounding the vasculature, but not in freshly infected cells. A lower level of expression was detected in the smaller uninfect- ed cells, cells of the inner cortex and a layer of cells in the outer cortex, but was absent in the root. GmVTL1a was co-localized with the endocytotic stain FM4-64 on the tonoplast and was also localized on the symbiosome membrane, similar to vacuole-residing proteins in the nodules of M. truncatula, by the mechanism of retargeting that is probably shared (Limpens et al., 2009; Gavrin, 2014). (Fig. 1).

Iron solubility and transport within and between plant tissues is facilitated by organic chelators, such as nicotianamine and citrate. Krivoruchko et al. (2018) characterized the nodule-specific citrate transporter of the multidrug and toxic compound extrusion family, MtMATE67 of M.truncatula. The MtMATE67 gene was induced early during nodule development and expressed primarily in the invasion zone of mature nodules. The MtMATE67 protein was located in the plasma membrane of nodule cells and also has been found in the symbiosome membrane surrounding bacteroids. In oocytes, MtMATE67 transported citrate out of cells in an iron-activated manner. Loss of MtMATE67 gene function resulted in accumulation of iron in the apoplast of nodule cells and a substantial decrease in symbiotic nitrogen fixation and plant growth. Taken together, the results point to a primary role of MtMATE67 in citrate efflux from nodule cells in response to an iron signal. This efflux is necessary to ensure the solubility of iron in $\mathrm{Fe}^{+}$form and its mobility in the apoplast and uptake into nodule cells. Likewise, MtMATE67-mediated citrate transport into the symbiosome space would increase the solubility and availability of $\mathrm{Fe}^{+}$for symbiosomes (Kryvoruchko et al., 2018) (Fig. 1).

Zinc is the cofactor of superoxide dismutases, which is an essential component of the cell's defense against reactive oxygen species (ROS). Zinc is essential for zinc-finger motif transcription factor (Rubio et al., 2007; González-Guerrero et al., 2014). As has been shown in the work of Abreu et al. (2017), zinc transporter MtZIP6 (Zinc-IronPermease6) is located in the plasma membrane of infected cells. MtZIP6 is responsible for zinc uptake from the apoplast and has a crucial role for root nodule nitrogen fixation. The silencing of MtZIP6 by method of RNA interference negatively affected the level of nitrogen fixation in silenced nodules (Abreu et al., 2017). (Fig. 1).

Calcium. The symbiotic signaling pathway starts with the oscillations of calcium ion concentration $\left(\mathrm{Ca}^{2+}\right)$ in the nucleus of root cells (Oldroyd, 2013). Nod factor-induced $\mathrm{Ca}^{2+}$ oscillations have been observed in M. truncatula (Wais et al., 2000), Pisum sativum (Walker et al., 2000), Phaseolus vulgaris (Cardenas et al., 1999) and Lotus japonicus (Harris et al., 2003). In a recent study, Granqvist et al. (2015) analyzed calcium responses in a variety of legumes and also in the nodulating non-legumes Parasponia andersonii and Alnus glutinosa. 
Granqvist et al. (2015) concluded that $\mathrm{Ca}^{2+}$ oscillations are a common feature of bacterial recognition within the nitrogen fixing clade and a conserved feature of bacterial recognition in all nodulating species analyzed. However, detailed information about the pathways of calcium transport to the infected cell of the root nodule and symbiosomes and putative carriers is limited. (Fig. 1).

Transport of metal ions by rhizobia. For information concerning the transport of metal ions by rhizobia, we would like to refer to the comprehensive review of Abreu et al. (2019). They described the data concerning metal ion transport in rhizobia ex-planta and partly the transport of ions most abundant in symbiosomes. Several families of transporters participating in the efflux/ influx of metal ions in rhizobia have been identified, though only few of them were found to be indispensable for the process of nitrogen fixation. These results show the complexity of ion membrane transport in infected cells. Bacteroids are completely dependent on the nutrients delivered by the plant. Hence, rhizobia performance in the nodules is quite different from growth conditions explanta (Abreu et al., 2019).

\section{In silico gene expression analysis of potassium/sodium ion transporters, channels and exchangers}

Potassium is not one of the metalloenzymes involved in the process of nitrogen fixation like nitrogenase or in the maintenance of oxygen levels like leggemoglobin. However, potassium is functional in osmoregulation, membrane transport and anion neutralization, as well as in the control of cytoplasmic and luminal $\mathrm{pH}$ in endosomes, regulation of membrane potential, and enzyme activity (Wang and Wu, 2013; Ragel et al., 2019). These are the functions that are crucial also for the root nodule and infected cell. Potassium $\left(\mathrm{K}^{+}\right)$is an essential macronutrient in plants. Potassium deficiency significantly reduces the potential for plant growth and development. By contrast, sodium $\left(\mathrm{Na}^{+}\right)$, while beneficial to some extent in the maintenance of cell turgor, at high concentrations disturbs and inhibits various physiological processes and plant growth. Some functions of $\mathrm{K}^{+}$can be undertaken by $\mathrm{Na}^{+}$but $\mathrm{K}^{+}$homeostasis is severely affected by salt stress (Adams and Shin, 2014). Maintenance of intracellular $\mathrm{K}^{+} / \mathrm{Na}^{+}$homeostasis is a crucial mechanism for plant growth and development.

It is a well-known fact that root nodules are more sensitive to stress caused by agents such as salt and heavy metals, than the roots of the host plant and the plant itself. Salt and heavy metals are detrimental for nodule formation and nitrogen fixing activity (Zahran, 1999; Tsyganov et al., 2007; Shvaleva et al., 2010; Coba de la Peña and Pueyo, 2012; Brear et al., 2013; Bertrand et al., 2016). It is quite possible that such a high vulnerability of the nodules is caused by spatial changes in $\mathrm{K}^{+} / \mathrm{Na}^{+}$ion homeostasis of infected tissue. With the aim of improving nodule stress tolerance, different works for selection and bio-engineering of host plants (Tsyganov et al., 2007, 2020; Coba de la Peña et al., 2010; Belimov et al., 2015) and microsymbionts (Domínguez-Fererras et al., 2009; Nonnoi et al. 2012; Quiñones et al. 2013) have been performed. Proteomics and transcriptomics techniques have been used to detect genes and proteins involved in stress tolerance of root nodules (Lu et al., 2017; Baig et al., 2018).

However, a comprehensive model of $\mathrm{K}^{+}$and $\mathrm{Na}^{+}$ transport and homeostasis in infected cells of the root nodule has not yet been developed.

Most of the current knowledge concerning ion transport of $\mathrm{K}^{+}$and $\mathrm{Na}^{+}$in plants has been obtained from studies using Arabidopsis thaliana as a model. The main families of $\mathrm{K}^{+}$-permeable transport systems include the families of HAK-KUP-KT transporters, Shaker-like $\mathrm{K}^{+}$ channels, HKT transporters, and cation-proton antiporters (CPA). The transport of $\mathrm{Na}^{+}$is mainly dependent on the transporters from the group of cation/proton exchangers/antiporters (Sze et al., 2018; Ragel et al., 2019; Villette et al., 2020).

Plant HAK-KUP-KT proteins. The transporters of the HAK-KUP-KT family are highly selective for $\mathrm{K}^{+}$and are crucial for organisms facing external solutions containing very low $\mathrm{K}^{+}$concentrations ( $\mu \mathrm{M}$ range). These transporters possess 10 to 14 transmembrane domains with both $\mathrm{N}$ - and C-termini at the membrane intracellular side. Members of this family have been widely associated with high-affinity $\mathrm{K}^{+}$uptake from the soil, and other roles related, for example, to $\mathrm{K}^{+}$translocation, control of water movement at the plant level, salt tolerance, osmotic/drought responses, transport of other alkali cations, and developmental processes in plants, such as root hair growth and auxin distribution (Li et al., 2018; Santa-Maria et al., 2018). These diverse functions of KT/ HAK/KUP transporters may all result from their critical roles in cellular $\mathrm{K}^{+}$homeostasis (Ragel et al., 2019).

Shaker channels are involved in a $\mathrm{K}^{+}$constant transport across the plasma membranes. Functional channels are tetrameric proteins arranged around a central pore and are composed by assembling four Shaker subunits encoded either by the same gene (homomeric channel) or by different genes (heteromeric channel) (Dreyer et al., 2004; Sharma et al.; 2013; Véry et al., 2014). Approximately $80 \%$ of high- and low-affinity $\mathrm{K}^{+}$uptake in Arabidopsis can be attributed to the sum of functions of AtAKT1 and AtHAK5 (a member of the HAK/KUP/KT family of transporters (Coskun and Kronzucker, 2013). The Shaker channel GORK, the outward $\mathrm{K}^{+}$channel, controls the closure of stomata in Arabidopsis. The opening of stomata are controlled by inward Shaker channels: KAT1, KAT2, and AKT1 (Lebaudy et al., 2008). These channels are also involved in phloem $\mathrm{K}^{+}$loading and unloading. In Vitis vi- 
Table 1. Transporters/channels/exchangers of potassium and

sodium of Arabidopsis thaliana and Medicago truncatula homologs

Arabidopsis thaliana protein/gene names in UniProt/

homolog of Medicago truncatula protein/gene names from Symbimics database

\begin{tabular}{|c|c|}
\hline GROUP 1 & GROUP 2 \\
\hline $\begin{array}{l}\text { Potassium transporter } 2 \text { (РОT2 KT2) / } \\
\text { Potassium transporter } 2 \text { (Medtr3g094090.1) }\end{array}$ & $\begin{array}{l}\text { Potassium transporter } 3 \text { (РОT3 КТ3) / } \\
\text { Potassium transporter } 3 \text { (Medtr8g099090) }\end{array}$ \\
\hline $\begin{array}{l}\text { Potassium transporter } 5 \text { (POT5 HAK5) / } \\
\text { Potassium transporter } 5 \text { (Medtr4g099260.1) }\end{array}$ & $\begin{array}{l}\text { Potassium transporter } 6 \text { (POT6 HAK6) / } \\
\text { Potassium transporter } 6 \text { (Medtr5g034500.1) }\end{array}$ \\
\hline $\begin{array}{l}\text { Potassium transporter } 8 \text { (РОT8 HAK8) / } \\
\text { Potassium transporter } 8 \text { (Medtr6g007697.1) }\end{array}$ & $\begin{array}{l}\text { Potassium transporter } 7 \text { (POT7 HAK7) / } \\
\text { Potassium transporter } 7 \text { (Medtr2g008820.1) }\end{array}$ \\
\hline $\begin{array}{l}\text { Potassium channel AKT1(AKT1 At2g26650) / } \\
\text { Potassium channel AKT1 (Medtr4g113530.1) }\end{array}$ & $\begin{array}{l}\text { Potassium channel GORK (GORK At5g37500) / } \\
\text { Potassium channel SKOR (Medtr5g077770.1) }\end{array}$ \\
\hline $\begin{array}{l}\text { Potassium channel AKT2/3 (AKT2 AKT3) / } \\
\text { Potassium channel AKT2/3 (Medtr2g006870.1) }\end{array}$ & $\begin{array}{l}\text { Sodium/hydrogen exchanger } 2 \text { (NHX2 At3g05030) / Sodium/ } \\
\text { hydrogen exchanger } 2 \text { (Medtr1g081900.1) }\end{array}$ \\
\hline $\begin{array}{l}\text { Potassium channel KAT1 (KAT1 At5g46240)/ } \\
\text { Potassium channel KAT1 X1 (Medtr8g446430.1) }\end{array}$ & $\begin{array}{l}\text { Sodium/hydrogen exchanger } 6 \text { (NHX6 At1g79610) / Sodium/ } \\
\text { hydrogen exchanger } 6 \text { (Medtr2g028230.1) }\end{array}$ \\
\hline $\begin{array}{l}\text { Potassium channel KAT3 (KAT3 AKT4) / } \\
\text { Potassium channel KAT3 (Medtr3g108320.1) }\end{array}$ & $\begin{array}{l}\text { Cation/H(+) antiporter } 21(\mathbf{C H X 2 1} \text { At2g31910) / } \\
\text { Cation/H(+) antiporter } 15 \text { (Medtr5g009770) }\end{array}$ \\
\hline $\begin{array}{l}\text { Sodium/hydrogen exchanger } 7 \text { (NHX7 SOS1) / } \\
\text { Putative potassium channel, voltage-dependent, } \\
\text { homolog of Sodium/hydrogen exchanger 7/ERG, cation/H+ } \\
\text { exchanger (Medtr2g038400.1) }\end{array}$ & $\begin{array}{l}\text { Cation/H(+) antiporter 17(CHX17 At4g23700) / } \\
\text { Cation/H(+) antiporter } 18 \text { (Medtr5g009770.4) }\end{array}$ \\
\hline \multicolumn{2}{|l|}{$\begin{array}{l}\text { Sodium transporter HKT1 (HKT1 At4g10310) / } \\
\text { Probable cation transporter HKT6 (Medtr6g092840.1) }\end{array}$} \\
\hline $\begin{array}{l}\text { Sodium/calcium exchanger NCL (NCL At1g53210) / } \\
\text { Sodium/calcium exchanger NCL (Medtr2g078240.1) }\end{array}$ & \\
\hline
\end{tabular}

nifera the homolog of AKT2 VvK3.1 channel mediates $\mathrm{K}^{+}$ unloading in the berries and also regulates the transmembrane $\mathrm{K}^{+}$gradients of phloem cells (Villette et al., 2020). SKOR Shaker-like $\mathrm{K}^{+}$outward rectifying channel in Arabidopsis mediates long-distance $\mathrm{K}^{+}$transport from roots to shoots, and it is a plasma membrane $\mathrm{Na}^{+} / \mathrm{H}^{+}$antiporter (Demidchik, 2018).

Cation $/ \mathrm{H}^{+}$antiporters (CPA). The group of $\mathrm{K}^{+}\left(\mathrm{Na}^{+}\right) / \mathrm{H}^{+}$exchangers (NHX) is a sub-group of $\mathrm{CPA}$ (Sze and Chanroj, 2018). Exclusion of sodium ions is one of the most important traits for salt tolerance in plants. Plant NHX antiporters are membrane proteins that transport protons $\left(\mathrm{H}^{+}\right)$across a membrane in exchange for $\mathrm{Na}^{+}$ or $\mathrm{K}^{+}$. Studies show that plant NHX antiporters are involved in the maintenance of cellular ion homeostasis and $\mathrm{pH}$ regulation, and play significant roles in diverse cellular processes, $\mathrm{Na}^{+}$and $\mathrm{K}^{+}$movement, vesicle trafficking and fusion, growth and development, and salt tolerance (Wu et al., 2016). In Arabidopsis these transporters are localized in different membrane compartments: SOS1/ AtNHX7 on the plasma membrane, AtNHX5/6 on endosomes, and AtNHX1-4 on the tonoplast (Chanroi et al., 2012). The mutations in the gene NHX7/SOS1 cause oversensitivity to salt due to disrupted efflux of sodium (Sze et al., 2004; Pardo et al., 2006, Bassil and Blumwald, 2014; Sandhu et al., 2018). Upregulation of NHX7/SOS1 was shown to be associated with salt tolerance in Medicago species (Liu et al., 2015; Sandhu et al., 2017). NHX1 and NHX2, localized in the tonoplast, are the two major NHX isoforms. These antiporters sequester $\mathrm{Na}^{+}$in vacuoles, which helps to maintain $\mathrm{Na}^{+} / \mathrm{K}^{+}$homeostasis (Bassil et al., 2011; Sandhu et al., 2018). NHX1 and NHX2 are essential for active $\mathrm{K}^{+}$uptake at the tonoplast and for turgor regulation (Barragan et al., 2012).

Data concerning $\mathrm{K}^{+}$and $\mathrm{Na}^{+}$transport in nodules are scarce (Benedito et al., 2010; Udvardi and Poole, 2013; Drain et al., 2020) and an integral picture of the transporters in infected cells is not yet available. With the aim of obtaining more information on $\mathrm{K}^{+}$and $\mathrm{Na}^{+}$ transport in the root nodule we have performed in silico gene expression analysis of $M$. truncatula $\mathrm{K}^{+}$and $\mathrm{Na}^{+}$ transporters/channels/exchangers using the database Symbimix, obtained by Laser-capture microdissection of root nodule zones (Roux et al., 2014). The genes of $\mathrm{K}^{+}$ and $\mathrm{Na}^{+}$transporters/channels/exchangers of A.thaliana were identified in the available genomic and cDNA sequence databases (https://www.uniprot.org). Selected protein sequences have been used for the search for M. truncatula homologs in public bioinformatic resources (https://phytozome.jgi.doe.gov/pz/portal and https://www.ncbi.nlm.nih.gov). The list of M. truncatula homologs and Arabidopsis genes is presented in Table 1. 


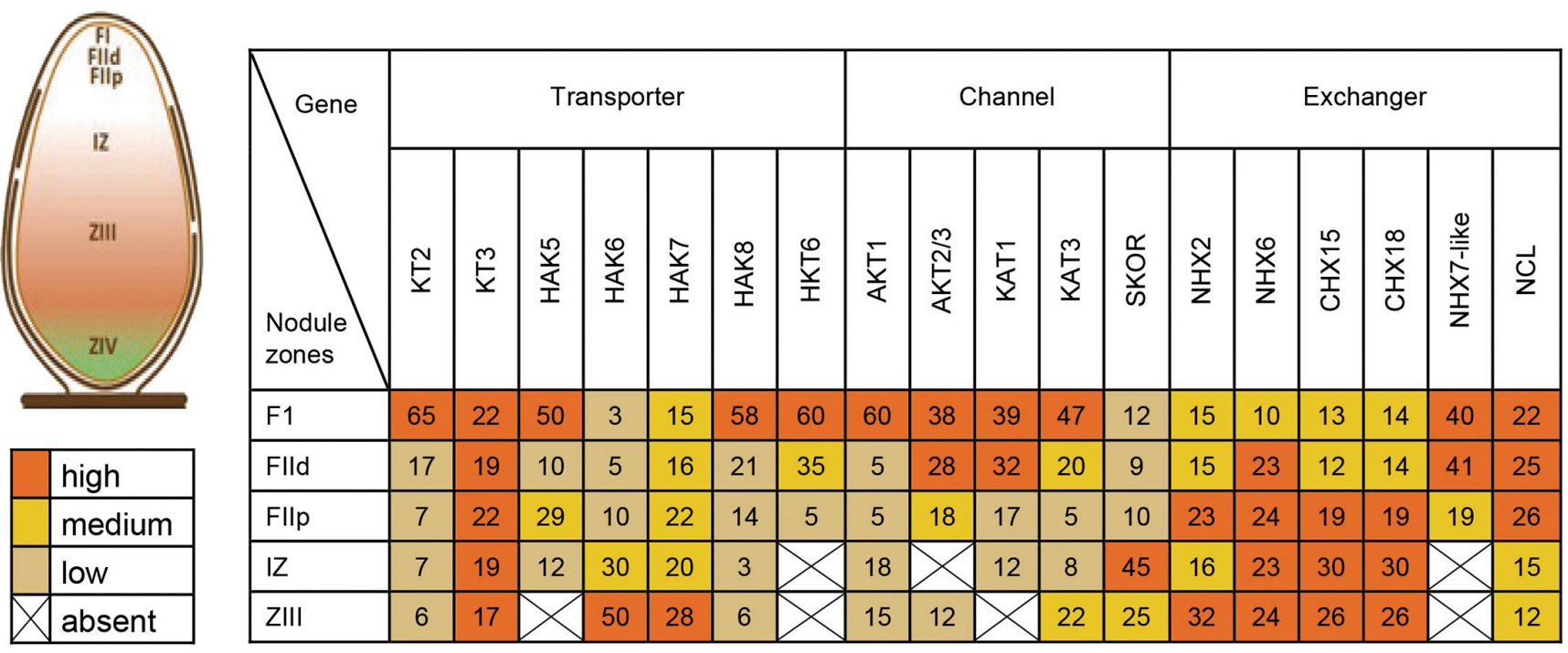

Fig. 2. Potassium and sodium channels, transporters, and exchangers transcripts expression in developmental zones of root nodule (derived from Symbimics database).

A more detailed description of the figure is given in the text.

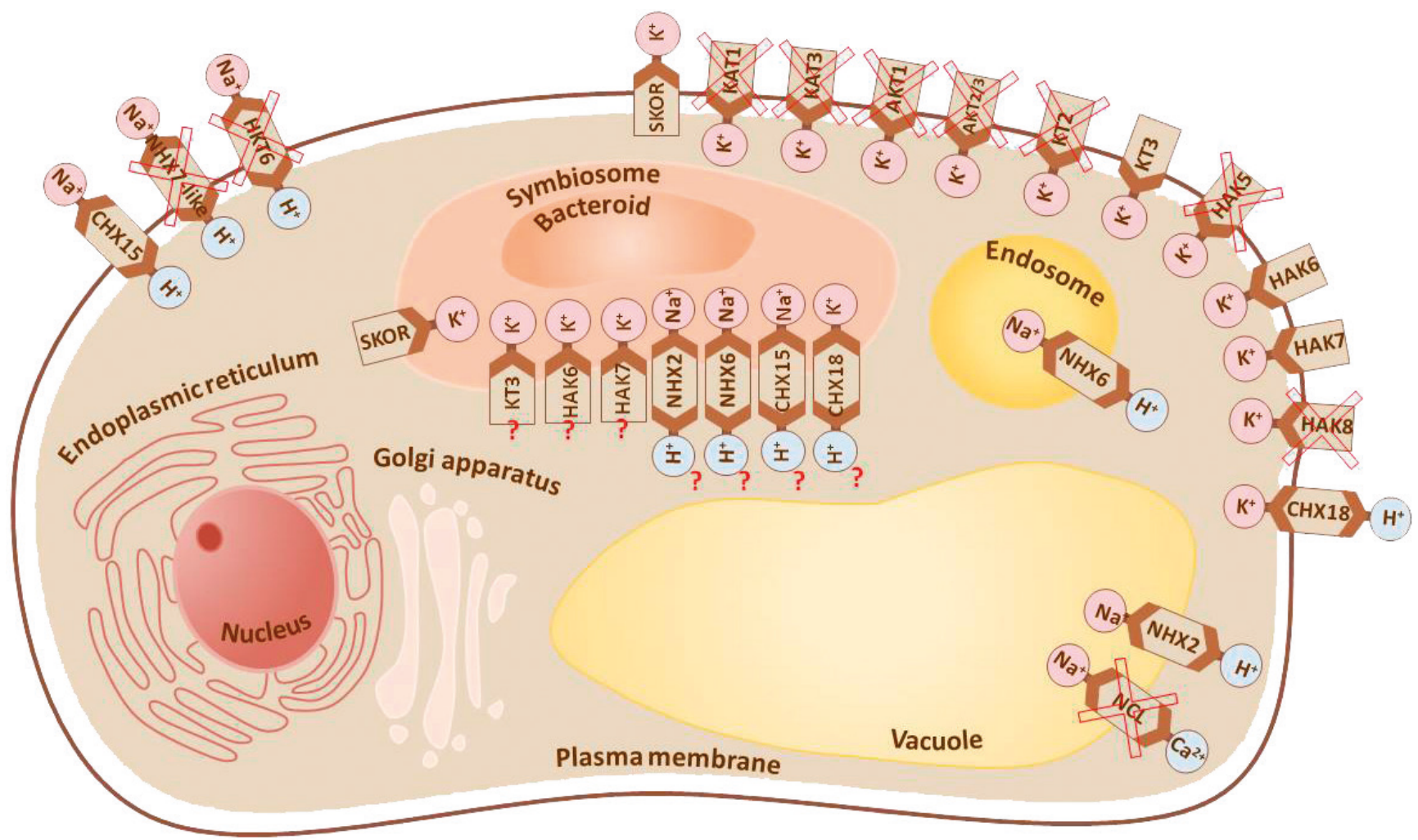

Fig. 3. The putative pattern of location of $\mathrm{K}^{+} / \mathrm{Na}^{+}$transporters in a mature infected cell.

AKT1, Potassium channel; AKT2/3, Potassium channel; CHX15, Cation/H+ exchanger 15; CHX17, Cation/H+ exchanger 17; CHX18, Cation/ H+ exchanger 18; HAK5, Sodium transporter 5; HAK6, Sodium transporter 6; HAK7, Sodium transporter 7; HAK8, Sodium transporter 8; KAT1, Potassium channel; KAT3, Potassium channel; KT2/KUP2, Potassium transporter; KT3/KUP4 (Tiny root hair 1 protein), Potassium transporter; NCL, Sodium/calcium exchanger; NHX2, Sodium/hydrogen exchanger 2; NHX6, Sodium/hydrogen exchanger 6; NHX7, Sodium/hydrogen exchanger 7; outward-rectifying potassium channel SKOR.

The levels of expression in silico of putative M. truncatula transporters/channels/exchangers have been estimated in nodule developmental zones according to Roux et al. (2014). These are: the nodule meristematic zone, termed as fraction I (FI); the region below FI, collected as a distal and a proximal fraction (FIId and FIIp), and corresponding to ZII cells undergoing differentiation or infection; the interzone II-III (IZ), which separates 
ZII from the nitrogen fixation zone ZIII (Vasse et al., 1990; Roux et al., 2014) (Table 1, Fig. 2). For group 1 in Table 1, transporters with low or absent expression in the nitrogen fixation zone (ZIII) were selected. In group 2 , the transporters with high stable expression level or upregulated in nitrogen fixation zone were excerpted. (Fig. 2). According to the expression analysis, all selected transporters, channels and exchangers showed expression in the meristematic and rapidly expanding cell layers of post-meristematic cells and young infected cells (F1, F2d, F2p, IZ) (Fig. 2). However, in the nitrogen fixation zone (ZIII) the expression was maintained only by a fraction of these genes.

The putative pattern of transporters/channels/exchangers' location in infected cell is presented in Figure 3. The transporters with a high level of expression in the zone of active nitrogen fixation (ZIII) were selected as candidate genes for the transporters in mature infected cells. The genes that showed high expression in the meristem of the nodule and young post-meristematic cells, but low or absent expression in ZIII, we consider to be not involved in the transport of $\mathrm{K}^{+}$and $\mathrm{Na}^{+}$in the zone of nitrogen fixation. In Figure 3 these genes are marked by crosses. To date, only the expression (Drain et al., 2020) and localization in the symbiosome membrane of Shaker-like $\mathrm{K}^{+}$outward rectifying channel SKOR/GORK, coded by a gene upregulated in IZ and ZIII, is confirmed (Fedorova et al., 2021). For the localization and expression of other genes experimental proof is still needed, so they are labelled with a question mark (Fig. 3).

For now, we cannot indicate the reasons for the differential expression of the transporters in ZIII. We also have no data to specify whether the level of expression of some genes coding for $\mathrm{K}^{+}$transport in mature infected cells is sufficient to meet the need for potassium of the infected cell and bacteria housed in it. However, some of the genes encoding Arabidopsis $\mathrm{K}^{+}$transporters, such as CHX17, HAK5 and KEA5, have been shown to be induced by $\mathrm{K}^{+}$deficiency (Adams and Shin, 2014). We can guess that an infected cell may experience limitations in $\mathrm{K}^{+}$in comparison with non-infected cells situated in the apical cell layers of the nodule that display a high level of expression of these transporters.

It is also quite interesting that exchangers/antiporters involved in the balance of sodium in the root nodule show substantial expression in the root nodule (Table 1). The expression of Sodium/hydrogen exchanger 2 (NHX2) (Medtr1g081900.1), and Sodium/ hydrogen exchanger 6 (NHX6) (Medtr2g028230.1) is upregulated in ZIII. This would be the expected outcome in case of applied salt, but it is puzzling why such an event is observed in untreated nodules. It is possible that the exchangers/antiporters coded by these genes could be involved in translocation of other ions required by infected cells, partly substituting the $\mathrm{K}^{+}$transporters coded by downregulated genes or the genes that stop being expressed in infected cells. The possibility that some portion of sodium ions may occasionally go through other ion channels, due to the similarity to potassium ions in size and charge, also cannot be excluded.

However, several genes, homologs of Arabidopsis genes involved in the $\mathrm{K}^{+} / \mathrm{Na}^{+} / \mathrm{H}^{+}$exchange and salt stress defense reaction, are not expressed in ZIII. These are the M.truncatula homolog (Medtr6g092840.1) of sodium transporter HKT1 (HKT1 At4g10310), which plays a central role in plant tolerance to salt (Rus et al., 2003) by translocation of $\mathrm{Na}^{+}$from the roots to the transpiring leaves, the M. truncatula homolog of NHX7/ AtSOS1 (Medtr2g038400.1), a main player in salt stress response, regulating the secretion of $\mathrm{Na}^{+}$from the cytoplasm to the extracellular space (Qiu et al., 2003), and the sodium/calcium exchanger NCL (Medtr2g078240.1) involved in $\mathrm{Na}^{+} / \mathrm{Ca}^{2+}$ homeostasis in stress conditions. It is interesting that these three genes code the plasmamembrane-located proteins functional in translocation of $\mathrm{Na}^{+}$across the plasma membrane. Due to this, the means for $\mathrm{Na}^{+}$detoxication via the plasma membrane in the zone of nitrogen fixation may become unavailable because $\mathrm{Na}^{+}$removal from the host cell cytoplasm is limited to the action of the exchangers located in the tonoplast and endosomes: Sodium/hydrogen exchanger 2 (Medtr1g081900.1) and Sodium/hydrogen exchanger 6 (Medtr2g028230.1). By analogy to Arabidopsis's homologs, these exchangers have to be functional in sequestering $\mathrm{Na}^{+}$in vacuoles and endosomes (Bassil et al., 2019). Vacuolar ion transport kinetics, including estimates of apparent $\mathrm{Km}$ for $\mathrm{K}^{+}$and $\mathrm{Na}^{+}$, indicated that these exchangers also mediate $\mathrm{K}^{+}$transport to the vacuoles in Arabidopsis, where NHX1, NHX2, and NHX4 are the main transporters mediating vacuolar $\mathrm{K}^{+}$uptake (Bassil et al., 2019). However, it is quite possible that the vacuolar exchanger MtNHX2 would have a low functionality in infected cells of $M$. truncatula due to the changing of vacuolar lumen $\mathrm{pH}$ in mature infected cells. The vacuoles of mature infected cells lose the acidic $\mathrm{pH}$ and become neutral or slightly basic (Gavrin et al., 2014). Therefore, it would be functional only in non-infected cells of the zone of nitrogen fixation. The above-described features of infected cells may partly explain the incapacity of these cells to manage salt stress. However, these hypothetical assumptions need further experimental verification. Concluding this part of the minireview we would like to point out that, as is shown by the in silico analysis presented above, the expression analysis that is routinely made on RNA extracted from the integral nodule does not accurately reflect the differences between different developmental zones of the nodule and between infected and non-infected cells. We believe that to obtain information concerning the real situation, a localization study on the cellular level is 
crucial. Research in this area is timely and can provide much needed information for improving the stress resistance of root nodules and increasing the duration of their functional activity.

\section{References}

Abreu, I., Saéz, Á., Castro Rodríguez, R., Escudero, V., Rodríguez Haas, B., Senovilla, M., and González Guerrero, M. 2017. Medicago truncatula Zinc Iron Permease6 provides zinc to rhizobia infected nodule cells. Plant, Cell \& Environment 40:2706-2719. https://doi.org/10.1111/pce.13035

Adams, E. and Shin, R. 2014. Transport, signaling, and homeostasis of potassium and sodium in plants. Journal of Integrative Plant Biology 56:231-249. https://doi. org/10.1111/jipb.12159

Baig, M. A., Ahmad, J., Bagheri, R., Ali, A. A., Al-Huqail, A. A., Ibrahim, M. M., and Qureshi, M. I. 2018. Proteomic and ecophysiological responses of soybean (Glycine max L.) root nodules to $\mathrm{Pb}$ and hg stress. BMC Plant Biology 18:121. https://doi.org/10.1186/s12870-018-1499-7

Bassil, E. and Blumwald, E. 2014. The ins and outs of intracellular ion homeostasis: $\mathrm{NHX}$-type cation $/ \mathrm{H}^{+}$transporters. Current Opinion in Plant Biology 22:1-6. https://doi. org/10.1016/j.pbi.2014.08.002

Bassil, E., Zhang, S., Gong, H., Tajima, H., and Blumwald, E. 2019. Cation specificity of vacuolar NHX-type cation $/ \mathrm{H}^{+}$ antiporters. Plant Physiology 179:616-629. https://doi. org/10.1104/pp.18.01103

Benedito, V. A., Li, H., Dai, X., Wandrey, M., He, J., Kaundal, R., and Zhao, P. X. 2010. Genomic inventory and transcriptional analysis of Medicago truncatula transporters. Plant Physiology 152(3):1716-1730. https://doi.org/10.1104/ pp.109.148684

Belimov, A. A., Malkov, N. V., Puhalsky, J. V., Safronova, V. I., and Tikhonovich, I. A. 2016. High specificity in response of pea mutant SGEC $d^{t}$ to toxic metals: Growth and element composition. Environmental and Experimental Botany 128:9198. https://doi.org/10.1016/j.envexpbot.2016.04.009

Bertrand, A., Bipfubusa, M., Dhont, C., Chalifour, F.P., Drouin, P., and Beauchamp, C.J. 2016. Rhizobial strains exert a major effect on the amino acid composition of alfalfa nodules under $\mathrm{NaCl}$ stress. Plant Physiology and Biochemistry 108:344-352. https://doi.org/10.1016/j.plaphy.2016.08.002

Brear, E. M., Day, D. A., and Smith, P. M. C. 2013. Iron: an essential micronutrient for the legume-rhizobium symbiosis. Frontiers in Plant Science 4:359. https://doi. org/10.3389/fpls.2013.00359

Brear, E. M., Gavrin, A., Kryvoruchko, I. S., Torres-Jerez, I., Udvardi, M., Day, D.A., and Smith, P. M. 2020. GmVTL1 is an iron transporter on the symbiosome membrane of soybean with an important role in nitrogen fixation. bioRxiv 2020.03.03.975805. https://doi. org/10.1101/2020.03.03.975805

Brewin, N. J. 2004. Plant cell wall remodelling in the Rhizobiumlegume symbiosis. Critical Reviews in Plant Sciences 23:293316. https://doi.org/10.1080/07352680490480734

Coba de la Peña, T. and Pueyo, J.J. 2012. Legumes in the reclamation of marginal soils, from cultivar and inoculant selection to transgenic approaches. Agronomy for Sustainable Development 32:65-91. https://doi.org/10.1007/ s13593-011-0024-2

Coba de la Peña, T., Fedorova, E., Pueyo, J. J., and Lucas, M. M. 2018. The symbiosome: legume and rhizobia co-evolution toward a nitrogen-fixing organelle? Frontiers in Plant Science 8:2229. https://doi.org/10.3389/fpls.2017.02229
Coba de la Peña, T., Redondo, F. J., Manrique, E., Lucas, M. M., and Pueyo, J.J. 2010. Nitrogen fixation persists under conditions of salt stress in transgenic Medicago truncatula plants expressing a cyanobacterial flavodoxin. Plant Biotechnology Journal 8:954-965. https://doi. org/10.1111/j.1467-7652.2010.00519.x

Curatti, L., Hernandez, J. A., Igarashi, R. Y., Soboh, B., Zhao, D., and Rubio, L. M. 2007. In vitro synthesis of the ironmolybdenum cofactor of nitrogenase from iron, sulfur, molybdenum, and homocitrate using purified proteins. Proceedings of the National Academy of Sciences USA 104:17626-17631. https://doi.org/10.1073/ pnas.0703050104

Demidchik, V. 2018. ROS-activated ion channels in plants: biophysical characteristics, physiological functions and molecular nature. International Journal of Molecular Sciences 19:1263. https://doi.org/10.3390/ijms19041263

Domínguez-Ferreras, A., Muñoz, S., Olivares, J., Soto, M.J., and Sanjuán J. 2009. Role of potassium uptake systems in Sinorhizobium meliloti osmoadaptation and symbiotic performance. Journal of Bacteriology 191:2133-2143. https://doi.org/10.1128/JB. 01567-08

Drain, A., Thouin, J., Wang, L., Boeglin, M., Pauly, N., NievesCordones, M., and Sentenac, H. 2020. Functional characterization and physiological roles of the single Shaker outward $\mathrm{K}^{+}$channel in Medicago truncatula. The Plant Journal 102:1249-1265. https://doi.org/10.1111/ tpj.14697

Escudero, V., Abreu, I., Tejada Jiménez, M., Rosa Núñez, E., Quintana, J., Prieto, R. I., and Argüello, J. M. 2020. Medicago truncatula Ferroportin2 mediates iron import into nodule symbiosomes. New Phytologist 228:194-209. https://doi.org/10.1111/nph.16642

Fedorova, E. E., Coba de la Peña, T., Lara-Dampier, V., Trifonova, N. A., Kulikova, O., Pueyo, J. J., and Lucas, M. M. 2021. Potassium content diminishes in infected cells of Medicago truncatula nodules due to the mislocation of channels MtAKT and MtSKOR/GORK. Journal of Experimental Botany eraa508. https://doi.org/10.1093/jxb/eraa508

Gavrin, A., Chiasson, D., Ovchinnikova, E., Kaiser, B. N., Bisseling, T., and Fedorova, E. E. 2016. VAMP 721a and VAMP $721 \mathrm{~d}$ are important for pectin dynamics and release of bacteria in soybean nodules. New Phytologist 210:10111021. https://doi.org/10.1111/nph.13837

Gavrin, A., Kulikova, O., Bisseling, T., and Fedorova, E. E. 2017. Interface symbiotic membrane formation in root nodules of Medicago truncatula: the role of synaptotagmins MtSyt1, MtSyt2 and MtSyt3. Frontiers in Plant Science 8:201. https://doi.org/10.3389/fpls.2017.00201

Ghosh, P. K. and Maiti, T.K. 2016. Structure of extracellular polysaccharides (EPS) produced by rhizobia and their functions in legume-bacteria symbiosis: A review. Achievements in the Life Sciences 10:136-143. https://doi. org/10.1016/j.als.2016.11.003

Gil Díez, P., Tejada Jiménez, M., León Mediavilla, J., Wen, J., Mysore, K. S., Imperial, J., and González Guerrero, M. 2019. MtMOT1.2 is responsible for molybdate supply to Medicago truncatula nodules. Plant, Cell \& Environment 42:310-320. https://doi.org/10.1111/pce.13388

Granqvist, E., Sun, J., Op den Camp, R., Pujic, P., Hill, L., Normand, P., Morris R. J., Downie J. A., GeurtsR., and Oldroyd, G. E. 2015. Bacterial induced calcium oscillations are common to nitrogen fixing associations of nodulating legumes and non legumes. New Phytologist 207:551558. https://doi.org/10.1111/nph.13464

Hakoyama, T., Niimi, K., Yamamoto, T., Isobe, S., Sato, S., Nakamura, Y., and Petersen, T. R. 2012. The integral membrane protein SEN1 is required for symbiotic nitrogen 
fixation in Lotus japonicus nodules. Plant and Cell Physiology 53:225-236. https://doi.org/10.1093/pcp/pcr167

Ivanov, S., Fedorova, E. E., Limpens, E., De Mita, S., Genre, A., Bonfante, P., and Bisseling, T. 2012. Rhizobium-legume symbiosis shares an exocytotic pathway required for arbuscule formation. Proceedings of the National Academy of Sciences USA 109:8316-8321. https://doi.org/10.1073/ pnas.1200407109

Kondorosi, E., Mergaert, P., and Kereszt, A. 2013. A paradigm for endosymbiotic life: cell differentiation of Rhizobium bacteria provoked by host plant factors. Annual Review of Microbiology 67:611-628. https://doi.org/10.1146/annurev-micro-092412-155630

Kronzucker, H. J., Coskun, D., Schulze, L. M., Wong, J. R., and Britto, D. T. 2013. Sodium as nutrient and toxicant. Plant and Soil 369:1-23. https://doi.org/10.1007/s11104-013-1801-2

Lebaudy, A., Véry, A. A., Sentenac, H. 2007. K+ channel activity in plants: genes, regulations and functions. FEBS Letters 581:2357-2366. https://doi.org/10.1016/j.febslet.2007.03.058

Limpens, E., Ivanov, S., van Esse, W., Voets, G., Fedorova, E., and Bisseling, T. 2009. Medicago $\mathrm{N}_{2}$-fixing symbiosomes acquire the endocytic identity marker Rab7 but delay the acquisition of vacuolar identity. The Plant Cell 21:2811-2828. https://doi.org/10.1105/tpc.108.064410

Lu, M., Jiao, S., Gao, E., Song, X., Li, Z., Hao, X., Rensing, C., Wei, G. 2017. Transcriptome response to heavy metals in Sinorhizobium meliloti CCNWSX0020 reveals new metal resistance determinants that also promote bioremediation by Medicago lupulina in metal-contaminated soil. Applied and Environmental Microbiology 83:e01244-17. https://doi.org/10.1128/AEM. 01244-17

Mendoza-Suárez, M. A., Geddes, B. A., Sánchez-Cañizares, C., Ramírez-González, R. H., Kirchhelle, C., Jorrin, B., and Poole, P.S. 2020. Optimizing Rhizobium-legume symbioses by simultaneous measurement of rhizobial competitiveness and $\mathrm{N}_{2}$ fixation in nodules. Proceedings of the National Academy of Sciences USA 117:9822-9831. https://doi.org/10.1073/pnas.1921225117

Mergaert, P., Kereszt, A., and Kondorosi, E. 2020. Gene expression in nitrogen-fixing symbiotic nodule cells in Medicago truncatula and other nodulating plants. The Plant Cell 32:42-68. https://doi.org/10.1105/tpc.19.00494

Nonnoi, F., Chinnaswamy, A., de la Torre, V.S.G., de la Peña, T. C., Lucas, M. M., and Pueyo, J. J. 2012. Metal tolerance of rhizobial strains isolated from nodules of herbaceous legumes (Medicago spp. and Trifolium spp.) growing in mercury-contaminated soils. Applied Soil Ecology 61:49-59. https://doi.org/10.1016/j.apsoil.2012.06.004

Oldroyd, G. E. D. 2013. Speak, friend, and enter: signalling systems that promote beneficial symbiotic associations in plants. Nature Reviews Microbiology 11:252-263. https:// doi.org/10.1038/nrmicro2990

Parniske, M. 2018. Uptake of bacteria into living plant cells, the unifying and distinct feature of the nitrogen-fixing root nodule symbiosis. Current Opinion in Plant Biology 44:164-174. https://doi.org/10.1016/j.pbi.2018.05.016

Qiu, Q.S., Guo, Y., Quintero, F.J., Pardo, J.M., Schumaker, K. S., and Zhu, J. K. 2004. Regulation of vacuolar $\mathrm{Na}^{+} /$ $\mathrm{H}^{+}$exchange in Arabidopsis thaliana by the salt-overlysensitive (SOS) pathway. Journal of Biological Chemistry 279:207-215. https://doi.org/10.1074/jbc.M307982200

Quiñones, M.A., Ruiz-Díez, B., Fajardo, S., López-Berdonces, M.A., Higueras, P. L., and Fernández-Pascual, M. 2013. Lupinus albus plants acquire mercury tolerance when inoculated with an Hg-resistant Bradyrhizobium strain. Plant Physiology and Biochemistry 73:168-175. https://doi.org/10.1016/j.plaphy.2013.09.015
Ragel, P., Raddatz, N., Leidi, E. O., Quintero, F. J., and Pardo, J. M. 2019. Regulation of $\mathrm{K}^{+}$nutrition in plants. Frontiers in Plant Science 10:281. https://doi.org/10.3389/ fpls.2019.00281

Rodríguez-Haas, B., Finney, L., Vogt, S., González-Melendi, P., Imperial, J., and González-Guerrero, M. 2013. Iron distribution through the developmental stages of Medicago truncatula nodules. Metallomics 5:1247-1253. https:// doi.org/10.1039/c3mt00060e

Roux, B., Rodde, N., Jardinaud, M. F., Timmers, T., Sauviac, L., Cottret, L., and Debellé, F. 2014. An integrated analysis of plant and bacterial gene expression in symbiotic root nodules using laser-capture microdissection coupled to RNA sequencing. The Plant Journal 77(6):817-837. https://doi.org/10.1111/tpj.12442

Roy, S., Liu, W., Nandety, R. S., Crook, A., Mysore, K. S., Pislariu, C. I., Frugoli J., Dickstein R., and Udvardi, M. K. 2020. Celebrating 20 years of genetic discoveries in legume nodulation and symbiotic nitrogen fixation. The Plant Cell 32:15-41. https://doi.org/10.1105/tpc.19.00279

Rubio, L. M. and Ludden, P. W. 2008. Biosynthesis of the ironmolybdenum cofactor of nitrogenase. Annual Review of Microbiology 62:93-111. https://doi.org/10.1146/annurev.micro.62.081307.162737

Santa-María, G. E., Oliferuk, S., and Moriconi, J. I. 2018. KT-HAKKUP transporters in major terrestrial photosynthetic organisms: A twenty years tale. Journal of Plant Physiology 226:77-90. https://doi.org/10.1016/j.jplph.2018.04.008

Senovilla, M., Castro-Rodríguez, R., Abreu, I., Escudero, V., Kryvoruchko, I., Udvardi, M. K., and González-Guerrero, M. 2018. Medicago truncatula copper transporter 1 (MtCOPT 1) delivers copper for symbiotic nitrogen fixation. New Phytologist 218:696-709. https://doi. org/10.1111/nph.14992

Sharma, T., Dreyer, I., and Riedelsberger, J. 2013. The role of $\mathrm{K}^{+}$channels in uptake and redistribution of potassium in the model plant Arabidopsis thaliana. Frontiers in Plant Science 4:224. https://doi.org/10.3389/fpls.2013.00224

Shvaleva, A., de la Peña, T. C., Rincón, A., Morcillo, C. N., de la Torre, V.S. G., Lucas, M. M., and Pueyo, J.J. 2010. Flavodoxin overexpression reduces cadmium-induced damage in alfalfa root nodules. Plant and Soil 326:109-121. https://doi.org/10.1007/s11104-009-9985-1

Sze, H. and Chanroj, S. 2018. Plant endomembrane dynamics: studies of $\mathrm{K}^{+} / \mathrm{H}^{+}$antiporters provide insights on the effects of $\mathrm{pH}$ and ion homeostasis. Plant Physiology 177:875-895. https://doi.org/10.1104/pp.18.00142

Tejada-Jiménez, M., Castro-Rodríguez, R., Kryvoruchko, I., Lucas, M. M., Udvardi, M., Imperial, J., and González-Guerrero, M. 2015. Medicago truncatula natural resistanceassociated macrophage Protein1 is required for iron uptake by rhizobia-infected nodule cells. Plant Physiology 168:258-272. https://doi.org/10.1104/pp.114.254672

Tsyganov, V. E., Belimov, A. A., Borisov, A. Y., Safronova, V. I., Georgi, M., Dietz, K.J., and Tikhonovich, I.A. 2007. A chemically induced new pea (Pisum sativum) mutant SGECd ${ }^{\mathrm{t}}$ with increased tolerance to, and accumulation of, cadmium. Annals of Botany 99:227-237. https://doi. org/10.1093/aob/mcl261

Tsyganov, V. E., Tsyganova, A. V., Gorshkov, A. P., Seliverstova, E. V., Kim, V. E., Chizhevskaya, E. P., Belimov, A. A., Serova, T. A., Ivanova, K. A., Kulaeva, O. A., Kusakin, P. G., Kitaeva, A. B., and Tikhonovich, I. A. 2020. Efficacy of a plant-microbe system: Pisum sativum (L.) cadmium-tolerant mutant and rhizobium leguminosarum strains, expressing pea metallothionein genes PsMT1 and PsMT2, for cadmium phytoremediation. Frontiers in Microbiology 11:15. https://doi.org/10.3389/fmicb.2020.00015 
Udvardi, M. and Poole, P. S. 2013. Transport and metabolism in legume-rhizobia symbioses. Annual Review of Plant Biology 64:781-805. https://doi.org/10.1146/annurevarplant-050312-120235

Vasse, J., De Billy, F., Camut, S., and Truchet, G. 1990. Correlation between ultrastructural differentiation of bacteroids and nitrogen fixation in alfalfa nodules. Journal of Bacteriology 172:4295-4306. https://doi.org/10.1128/ jb.172.8.4295-4306.1990

Véry, A. A., Nieves-Cordones, M., Daly, M., Khan, I., Fizames, C., and Sentenac, H. 2014. Molecular biology of $\mathrm{K}^{+}$transport across the plant cell membrane: what do we learn from comparison between plant species? Journal of Plant Physiology 171:748-769. https://doi.org/10.1016/j. jplph.2014.01.011

Villette, J., Cuellar, T., Verdeil, J. L., Delrot, S., and Gaillard, I. 2020. Grapevine potassium nutrition and fruit quality in the context of climate change. Frontiers in Plant Science 11:123. https://doi.org/10.3389/fpls.2020.00123

Walker, S. A., Viprey, V., and Downie, J. A. 2000. Dissection of nodulation signaling using pea mutants defective for calcium spiking induced by Nod factors and chitin oligomers. Proceedings of the National Academy of Sciences USA 97:13413-13418. https://doi.org/10.1073/ pnas. 230440097

Wang, Y. and Wu, W. H. 2015. Genetic approaches for improvement of the crop potassium acquisition and utilization efficiency. Current Opinion in Plant Biology 25:4652. https://doi.org/10.1016/j.pbi.2015.04.007

Wang, Y. and Wu, W. H. 2013. Potassium transport and signaling in higher plants. Annual Review of Plant Biology 64:451-476. https://doi.org/10.1146/annurev-arplant-050312-120153

Wu, X., Ebine, K., Ueda, T., and Qiu, Q. S. 2016. AtNHX5 and AtNHX6 are required for the subcellular localization of the SNARE complex that mediates the trafficking of seed storage proteins in Arabidopsis. PLoS One 11:e0151658. https://doi.org/10.1371/journal.pone.0151658

Zahran, H. H. 1999. Rhizobium-legume symbiosis and nitrogen fixation under severe conditions and in an arid climate. Microbiology and Molecular Biology Reviews 63:968989. https://doi.org/10.1128/MMBR.63.4.968-989.1999 